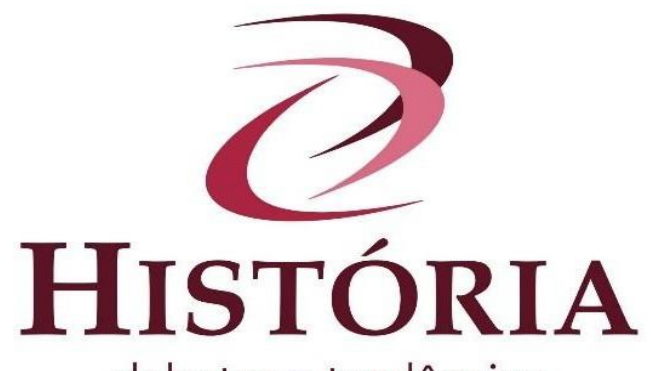

\title{
Os paradoxos do agronegócio fumageiro entre os pequenos agricultores no oeste de Santa Catarina
}

\section{The paradoxes of tobacco agribusiness among smallholder farmers in western Santa Catarina}

\section{Las paradojas de fumar agroindustria entre los pequeños agricultores en el oeste de Santa Catarina}

\author{
Arlene Renk* \\ Silvana Winckler**
}

\begin{abstract}
Resumo: O texto aborda os "desencontros" das políticas brasileiras em relação à ConvençãoQuadro para o Controle do Tabaco (CQCT), sob auspícios da Organização Mundial da Saúde, ratificada pelo Brasil em 2005. Um dos pontos de embate está na diminuição/erradicação do cultivo do tabaco. O governo brasileiro, numa postura politicamente correta, bane o fumo do espaço público, diminui o número de fumantes, mas oficialmente estimula o cultivo do tabaco para o incremento da balança comercial. Apesar da ratificação da Convenção pelo Brasil, encontramos o cultivo em pequena propriedade, em trabalho familiar, com alta carga de agrotóxico, em integração com a agroindústria fumageira, ou seja, agronegócio, pouco lembrado, quando mencionado. A relação de integração vertical transforma o fumo em primo pobre do agronegócio, em relação aos avicultores e suinocultores, face ao baixo grau de capitalização das famílias integradas. A pesquisa é de caráter qualitativo, envolvendo dois municípios. Entrevistamos vinte fumicultores e quatro lideranças sindicais. Recorremos igualmente a fontes documentais e estatísticas para complementação e aprofundamentos dos dados obtidos em campo. A pesquisa encontra-se em fase de andamento. Como resultados preliminares, observamos que o cultivo do fumo não é opção dos pequenos agricultores, mas uma das únicas saídas encontradas para permanecer na agricultura. Agricultores com maior grau de capitalização recusam-se ao plantio do fumo. As políticas públicas têm olhar oblíquo em relação aos fumicultores.
\end{abstract}

Palavras-chave: Integração vertical. Tabaco. Agricultura Familiar.

Abstract:The text addresses the "mismatches" of Brazilian policies regarding the Framework Convention on Tobacco Control (FCTC), under the auspices of the World Health Organization, ratified by Brazil in 2005. One of the points of conflict is the decrease / eradication of tobacco cultivation. The Brazilian government, in a politically correct stance, bans smoking from public space, decreases the number of smokers, but officially encourages tobacco cultivation to increase the trade balance. Despite the ratification of the Convention by Brazil, we find the cultivation in small property, in family work, with high pesticide load, in integration with the tobacco industry, that is, agribusiness, little remembered, when mentioned. The relationship of vertical integration turns tobacco into a poor cousin of agribusiness, in relation to poultry and pig farmers, given the low capitalization of integrated families. The research is qualitative, involving two municipalities. We interviewed twenty tobacco farmers and four union leaders. We also 
used documentary and statistical sources to complement and deepen the data obtained in the field. The research is in progress. As preliminary results, we note that tobacco growing is not an option for small farmers, but one of the only ways out to stay in agriculture. Farmers with higher capitalization refuse to plant tobacco. Public policies have an oblique look towards tobacco growers.

Keywords: Vertical integration. Tobacco. Family Farming.

RESUMEN: El texto aborda los "desajustes" de las políticas brasileñas con respecto al Convenio Marco para el Control del Tabaco, bajo los auspicios de la Organización Mundial de la Salud, ratificado por Brasil en 2005. El gobierno brasileño condena fumar, pero oficialmente estimula el cultivo de tabaco para aumentar la balanza comercial. La investigación es cualitativa, involucrando a dos municipios en el oeste de Santa Catarina. Veinte productores de tabaco y cuatro líderes sindicales fueron entrevistados. Se utilizaron fuentes documentales y estadísticas para complementar y profundizar los datos obtenidos en el trabajo de campo. La investigación está en progreso. Como resultados preliminares, observamos que el cultivo de tabaco no es una opción para los pequeños agricultores, sino una de las únicas formas de mantenerse en la agricultura.

Palabras clave: Agricultura Familiar. Integración Vertical.

\section{Introduzindo}

O Brasil figura como o segundo maior produtor e o primeiro no ranking de exportação mundial de tabaco ${ }^{i}$, posição mantida há vinte e seis anos, a mesma idade da ratificação da Convenção-Quadro para o Controle do Fumo (CQCT). Para o setor do agronegócio essa posição pode ser motivo de comemoração e de solidez da posição brasileira ante o mercado internacional. Para outros setores, principalmente aqueles que representam a esfera da saúde, demonstra a fragilidade da efetividade das políticas em relação a um elo da cadeia produtiva, exatamente o do produtor, no campo. O tabaco já foi conhecido como erva santa, de miraculosas propriedades terapêuticas do século XVII (LAPA, 1968), converteu-se num dos malefícios combatidos pela Organização Mundial da Saúde, atribuindo ao tabagismo o rótulo de epidemia mundial, pelos danos diretos e indiretos que desencadeia. Embora seu cultivo, em grande parte, seja realizado por pequenos agricultores, faz parte do agronegócio. Ocupam-se com esta lavoura pequenos agricultores, que não dispõem de áreas ou de recursos financeiros suficientes para diversificação de cultivo. Ao menos é o que ocorre no Oeste de Santa Catarina, locus deste estudo.

Este texto pretende discutir os "desencontros" das políticas brasileiras em relação à Convenção-Quadro para o Controle do Tabaco (CQCT), sob auspícios da Organização Mundial da Saúde, ratificada pelo Brasil em 2005. Um dos pontos de embate está na diminuição/erradicação do cultivo do tabaco. O governo brasileiro, numa mão, bane o fumo do espaço público, tem programas de saúde para combate ao tabagismo, combate o contrabando do cigarro, diminui o número de fumantes (VIGITEL, 2018); noutra mão, acena favoravelmente ao crescimento da produção do tabaco em aproximadamente $16 \%$ no próximo decênio, como imperativo de contribuição à balança 
comercial e ao incremento da renda familiar dos agricultores (MINISTÉRIO DA AGRICULTURA, PECUÁRIA E ABASTECIMENTO, 2017; 2018).

Em termos metodológicos, centramos nossos esforços no trabalho de campo, tomando como objeto a fumicultura no oeste catarinense, sem desconsiderar seus nexos com o mercado internacional, levando em conta os pequenos produtores do agronegócio, a fim de observar como rebatem os "desencontros" mencionados. Recorremos a dados estatísticos, já organizados pela Associação dos Fumicultores do Brasil (AFUBRA), à bibliografia disponível, entrevistando vinte fumicultores/fumicultoras e quatro dirigentes sindicais. Para tal, selecionamos no oeste catarinense, cuja composição étnica foi predominantemente de descendentes de italianos. A economia local e regional centra-se predominantemente na avicultura e suinocultura, em integração vertical, e na produção de leite. Na seleção dos entrevistados adotamos como critério entrevistar agricultores e agricultoras que estavam na atividade fumageira há mais de cinco anos, independente de consorciação com outra atividade produtiva. Trata-se de projeto em andamento, apresentando aqui apenas resultados parciais.

\section{Da Bahia ao Sul}

Recorrer ao aspecto histórico, mesmo que brevemente, interessa-nos para não absolutizar os dados obtidos em campo e informações da literatura. O historiador Jose Roberto do Amaral Lapa registrava que na Bahia do século XVII, além do valor comercial, se atribuía ao tabaco propriedades terapêuticas. Era conhecido como erva santa, erva sacra ou erva divina (LAPA, 1968, p. 84), sem a concordância da Igreja, o que mais uma vez aponta que o mundo social é um campo de lutas entre as representações e imposições de verdades. O que houve com o tabaco foi um itinerário de reconversão ao estigma atual, mas mantendo uma invariante: ser considerado um plantio dos pobres, podia e pode ser realizado em pequenas áreas e até hoje, naquele estado, ocorre nas franjas das fazendas. Nos séculos iniciais o cultivo era desconcentrado nas diversas províncias do reino, com hegemonia na Bahia. Nunca figurou num "ciclo econômico".

Foi considerado o "primo pobre" (LAPA, 1968; ACIOLI, 2005) do setor açucareiro, mas nem por isso deixou de ser moeda para transação de escravos. No século XVIII o porto de Salvador era o maior exportador de tabaco e receptador de escravos. Bahia era o maior produtor, mas não o único.

No período colonial, mesmo considerado lavoura dos pobres, requeria a mão-de-obra escrava e dependia do crédito do atravessador. Nesse período histórico, a presença de escravos é 
uma invariante apontada pelos historiadores. Lapa (1968) afirma que em algumas propriedades chegava a haver presença de dezesseis escravos. Para assegurar a produtividade do tabaco, procediam à adubação do solo, o que o diferenciava do da cana, exaurido. A respeito da " lavra do fumo" o Padre Antonil, em Cultura e Opulência do Brasil, registrou que no sertão da Bahia passou a ser um "dos gêneros de maior estimação" (...) E desta sorte huma folha de antes desprezada, e quase desconhecida, tem dado, e dá actualmente grandes cabedais aos moradores do Brazil, e incríveis emolumentos ao erário dos príncipes" (ANTONIL, 1837 [1711] p. 118).

O historiador econômico Caio Prado Junior (2004) reitera Lapa (1968) quanto à posição periférica do tabaco, cultivado em pequenas áreas, com pequenos "planteis de escravos", opondose ao sistema de plantation da cana. Também foi chamado "cultura de jardinagem", pelo cuidado que exige a cada planta. Nardi (1987) explica que, diferentemente do cultivo da cana, com solo exaurido, tabaco era adubado a cada safra.

Nas primeiras décadas do século XX observou-se o fenômeno da desconcentração da produção do tabaco do nordeste e o deslocamento desse centro produtivo ao sul do Brasil (NARDI, 1987). No Rio Grande do Sul, a presença do fumo entre os agricultores alemães e seus descendentes no século XIX, mais fortemente no Vale do Rio Pardo (VOGT, 1997; BOEIRA 2000; 2006; CUNHA, 1998; ROCHE 1969). Os registros apontam que a produção do fumo esteve presente nas primeiras horas na Colônia de Santa Cruz do Sul "resultado da intervenção combinada da administração colonial e do Capital no processo produtivo que na fase seguinte do desenvolvimento econômico de Santa Cruz determinará a especialização de sua produção” (CUNHA, 1998, p. 174.). Nas áreas de colonização era proibido o trabalho escravo. A atividade no fumo era uma atividade familiar, típica das práticas camponesas, hierarquizada, sob a administração do pai de familiar, incluindo as forças plenas e marginais.

A literatura a respeito do campesinato explica a conjugação dos esforços da agricultura familiar, em auto exploração, da figura complexa que reside na conjugação da força de trabalho, de organização de suas atividades, mas estar, simultaneamente, em relação de subordinação, recebendo o epíteto de "inclassificável" (GRIGNON, 1975). É esse contingente populacional que preencheu os requisitos para pavimentar o mercado e a industrialização do tabaco no sul do país.

O Vale do Rio Pardo tornou-se uma área de concentração de fumicultura. No início do século XX a Souza Cruz instalou-se em Santa Cruz do Sul, seguida de outras empresas nacionais e estrangeiras. Segundo sítio da Souza Cruz, em 1918 teria sido lançada a integração por Albino Souza Cruz e que persiste até hoje.

No oeste catarinense, área de estudo, região de colonização tardia, com agricultores que migraram de várias regiões do Rio Grande do Sul em busca de terras, como estratégia de reprodução social camponesa, a partir das primeiras décadas do século XX, o fumo em folhas era repassado aos 
comerciantes que o revendiam aos centros maiores. O que não havia era a obrigatoriedade de entregar o produto a determinado comerciante, salvo que houvesse compromisso de dívida ou de lealdade. Com a introdução da Revolução Verde, a agricultura passou por transformações. À medida que a pequena propriedade se subordina ao sistema mundial (SZMRECSÁNYI, 1990), pelos ditames da Revolução Verde, uma das consequências é a perda da autonomia (embora nunca fosse absoluta) e a implantação da integração vertical com as agroindústrias.

A Revolução Verde introduz novas formas de plantar, homogeneizando os procedimentos, substituindo os cultivares, introduzindo sementes, insumos, assistência técnica, agroquímicos e o fundamental: o contrato com a integradora. A relação contratual substitui a anterior relação, com o comerciante ou bodegueiro, realizada na informalidade. Estabelece-se um vínculo que, à primeira vista, ao agricultor, significa ter a garantia de haver comprador para a safra, mas apresenta o reverso da moeda: os liames da dependência creditícia exigida pela atividade e a orientação técnica, que deixa de ser uma orientação e transforma-se numa obrigação de seguir os procedimentos da integradora. Registre-se que a integradora é sempre uma transnacional do tabaco, à medida que as empresas nacionais ou foram incorporadas ou mantiveram-se em segundo plano. Paulillo (1990) e Vogt (1997) estudaram o processo da integração vertical da fumicultura, respectivamente, em Santa Catarina e no Rio Grande do Sul, detalhando os meandros da entrada das integradoras na propriedade familiar e da crescente exigência dos padrões de cultivo, levando os agricultores integrados à subordinação. Ressalte-se o processo de integração não se diferencia em função do produto, porque os elementos são invariantes: trabalho familiar, insumos fornecidos pela integradora, orientação técnica, padrão de produção e aquisição do produto pela integradora. A integração da avicultura e da suinocultura obedecerá aos mesmos princípios, com a ressalva de que estas exigem montante elevado de capital para a infraestrutura, age num processo seletivo, à medida que exclui os agricultores de menor capitalização.

No caso em estudo, a integração da fumicultura é novamente a dos "primos pobres". Participam aqueles que não foram incluídos na avicultura, na suinocultura ou na produção de grãos em escala. À falta de outras atividades, ou por não conseguirem manter-se em atividades alternativas que demandam capital, voltam-se ao tabaco.

Os dados apresentados pela AFUBRA indicam que na safra de 2017/18 os três estados sulistas participaram com $97 \%$ da produção do tabaco produzido no país, ao passo que nordeste contribuiu com 2,9\%, o que se traduz em 149.350 famílias no primeiro grupo e 9.997 no segundo grupo.

\section{Quadro 1 - Fumicultura Brasileira}




\begin{tabular}{|c|c|c|c|c|c|c|c|c|}
\hline \multicolumn{9}{|c|}{ FUMICULTURA BRASILEIRA } \\
\hline \multicolumn{9}{|c|}{ Safra: $2017 / 18$} \\
\hline \multirow{2}{*}{ REGIÃO } & \multirow{2}{*}{\begin{tabular}{|l} 
No de \\
Estados
\end{tabular}} & \multirow{2}{*}{\begin{tabular}{|l} 
FAMíLIAS \\
produtoras \\
\end{tabular}} & \multirow{2}{*}{\begin{tabular}{|l} 
HA \\
plantados \\
\end{tabular}} & \multirow{2}{*}{\begin{tabular}{|l} 
PRODUÇÃO \\
Toneladas \\
\end{tabular}} & \multirow{2}{*}{$\begin{array}{l}\text { Partic. } \\
\% \\
\end{array}$} & \multirow{2}{*}{$\mathrm{kg} / \mathrm{ha}$} & \multicolumn{2}{|c|}{ VALOR } \\
\hline & & & & & & & $\mathrm{R} \$ / \mathrm{kg}$ & Total \\
\hline Sul & 3 & 149.350 & 297.460 & 685.983 & 97,0 & 2.306 & 9,15 & 6.278 .431 .841 \\
\hline Nordeste & 7 & 9.997 & 16.357 & 20.707 & 2,9 & 1.266 & 7,66 & 158.706 .137 \\
\hline Outras & 4 & 263 & 358 & 344 & 0,0 & 960 & 17,19 & 5.913 .661 \\
\hline TOTAL & 14 & 159.610 & 314.175 & 707.034 & 100 & 2.250 & 9,11 & 6.443.051.638 \\
\hline
\end{tabular}

Fonte. AFUBRA, 2018

No Quadro 2 observa-se, à primeira vista, que as safras de 2017 e 2018 são aquelas com maior rendimento por hectare: 2.365 e $2.306 \mathrm{~kg}$, respectivamente. Depois de elevação no número de produtores em 2005 e 2009, o quadro apresenta uma tendência à diminuição, condizente com o preceito da Afubra, da melhoria da qualidade e manter a área plantada ou diminui-la. 
Quadro 2 - Evolução do fumicultura

\begin{tabular}{|c|c|c|c|c|c|c|}
\hline \multicolumn{7}{|c|}{ FUMICULTURA SUL-BRASILEIRA } \\
\hline \multicolumn{7}{|l|}{ Evolução } \\
\hline \multirow{2}{*}{ SAFRA } & \multirow{2}{*}{$\begin{array}{l}\text { FAMÍLIAS } \\
\text { produtoras }\end{array}$} & \multirow{2}{*}{\begin{tabular}{|l} 
HECTARES \\
plantados
\end{tabular}} & \multirow{2}{*}{$\begin{array}{l}\text { PRODUÇÃO } \\
\text { TON } \\
\end{array}$} & \multirow{2}{*}{$\mathrm{kg} / \mathrm{ha}$} & \multicolumn{2}{|c|}{ VALOR } \\
\hline & & & & & $\mathrm{R} \$ / \mathrm{kg}$ & Total \\
\hline 2018 & 149.350 & 297.460 & 685.983 & 2.306 & 9,15 & $6.278 .431 .840,85$ \\
\hline 2017 & 150.240 & 298.530 & 705.930 & 2.365 & 8,63 & $6.090 .633 .962,38$ \\
\hline 2016 & 144.320 & 271.070 & 525.221 & 1.938 & 9,96 & $5.230 .364 .810,00$ \\
\hline 2015 & 153.730 & 308.260 & 697.650 & 2.263 & 7,13 & $4.976 .704 .200,00$ \\
\hline 2014 & 162.410 & 323.700 & 731.390 & 2.259 & 7,28 & $5.321 .932 .174,00$ \\
\hline 2013 & 159.595 & 313.675 & 712.750 & 2.272 & 7,45 & $5.309 .987 .500,00$ \\
\hline 2012 & 165.170 & 324.610 & 727.510 & 2.241 & 6,30 & $4.583 .313 .000,00$ \\
\hline 2011 & 186.810 & 372.930 & 832.830 & 2.233 & 4,93 & $4.105 .851 .900,00$ \\
\hline 2010 & 185.160 & 370.830 & 691.870 & 1.866 & 6,35 & 4.393.374.500,00 \\
\hline 2009 & 186.580 & 374.060 & 744.280 & 1.990 & 5,90 & $4.391 .252 .000,00$ \\
\hline 2008 & 180.520 & 348.720 & 713.870 & 2.047 & 5,41 & $3.862 .036 .700,00$ \\
\hline 2007 & 182.650 & 360.910 & 758.660 & 2.102 & 4,25 & 3.224.305.000,00 \\
\hline 2006 & 193.310 & 417.420 & 769.660 & 1.844 & 4,15 & 3.194.089.000,00 \\
\hline 2005 & 198.040 & 439.220 & 842.990 & 1.919 & 4,33 & $3.650 .146 .700,00$ \\
\hline 2000 & 134.850 & 257.660 & 539.040 & 2.092 & 2,00 & $1.078 .080 .000,00$ \\
\hline 1995 & 132.680 & 200.830 & 348.000 & 1.733 & 1,55 & $539.400 .000,00$ \\
\hline
\end{tabular}

Fonte: AFUBRA, 2018

A observação do INCA acompanhando os dados da produção da fumicultura merece registro. "O aumento de produção, registrado entre 2016 e 2017, se deu em função do ingresso de 5.000 famílias na produção, pela falta de acesso às chamadas de assistência técnica à diversificação da Secretaria Especial de Agricultura Familiar da Casa Civil do PR e pelo leve aumento de demanda apresentado pelos Estados Unidos da América." (https://www.inca.gov.br/en/node/1419. $04 / 02 / 2019)$

Com avanços e recuos, há entradas de famílias, retiradas de outras, nunca alcançando o patamar de 
2005, mas longo do que significa a erradicação do cultivo.

\section{As controvérsias e as faces de Jano}

A erva santa, que no Brasil colonial chegou a ter status terapêutico, transformou-se em causadora de doenças desencadeadas pelo tabagismo, considerado epidemia mundial. Os gastos dos Estados com saúde alcançaram e alcançam cifras consideráveis e poderiam ser combatidos pela mudança no padrão de consumo e pela evitação ao tabagismo. A Organização Mundial de Saúde (OMS), órgão da ONU, com sede em Genebra, desencadeou as discussões que resultaram na formatação da Convenção-Quadro para o Controle do Tabaco. Um dos argumentos utilizados, não o único, foi o do alto investimentos dos Estados no tratamento das doenças desencadeadas pelo fumo, direta ou indiretamente. As reuniões internacionais foram orientadas para a discussão da temática, qualificando o tabagismo como epidemia internacional. Resultaram nas "Conferências a respeito do fumo e saúde", dando origem a resoluções antitabaco que subsidiaram a ConvençãoQuadro para o Controle do Tabaco, documento aprovado na Assembleia Mundial da Saúde ONU em 1999.

Na primeira hora, em 1999, quando da Assembleia Mundial de Saúde, o Brasil assinou a Convenção. A ratificação do governo brasileiro à Convenção-Quadro ocorreu apenas em 2005 (Decreto n. $5.658 \mathrm{em} 2$ de janeiro de 2006), comprometendo-se a aceitar as cláusulas do documento ${ }^{\text {ii }}$. Declaradamente, a OMS e os interesses da indústria fumageira são conflitivos, jogam em campos opostos, o que não impede que as corporações mudem seus discursos e criem estratégias de esverdeamento ${ }^{\mathrm{iii}}$.

Um dos pontos da Convenção consiste nas medidas de combate, diminuição e erradicação do cultivo do tabaco e no investimento em instituições de cunho terapêutico para a cura do câncer. Isso significa dizer, coibir práticas de tabagismo. Coaduna-se atualmente com o Objetivo de Desenvolvimento Sustentável das Nações Unidas (ODS) n ${ }^{\circ} 3$ - sobre saúde e bem-estar - que prevê redução em um terço das mortes causadas por enfermidades não transmissíveis.

No âmbito da execução, no caso brasileiro, há a Comissão Nacional para Implementação da Convenção-Quadro (CONICQ), que é responsável por articular a implementação da agenda governamental para o cumprimento dos artigos do Tratado. É presidida pelo Ministro de Estado da Saúde e composta por representantes de 18 Órgãos e Ministérios. Decorrido um decênio, observase que a produção do tabaco brasileiro ocupa lugar de proeminência internacional, como o segundo maior produtor e maior exportado. Diante disso, perguntamo-nos, não consiste em paradoxo o Brasil ter ratificado a Convenção-Quadro, ter uma política de saúde respaldada nesse sentido, investir no 
combate ao contrabando dos cigarros e ao tabagismo e, no entanto, não ter rebatimentos no setor produtivo do tabaco?

Em relação aos fumicultores, a Convenção-Quadro para o Controle do Tabaco prevê a transição para atividade econômica sustentável:

Devem ser reconhecidos e abordados, no contexto das estratégias nacionais de desenvolvimento sustentável, a importância da assistência técnica e financeira para auxiliar a transição econômica dos produtores agrícolas e trabalhadores cujos meios de vida sejam gravemente afetados em decorrência dos programas de controle do tabaco, nas Partes que sejam países em desenvolvimento, e nas que tenham economias em transição. (CQCT Art. 4.n.6)

Como foi constatado anteriormente, embora com oscilações, o quadro da produção da fumicultura não tem apresentado redução sensível desde o ano 2.000. Naquele ano tivemos 132.680 fumicultores com produtividade de $2.092 \mathrm{~kg} / \mathrm{h}$, números que cresceram para 149.350 produtores, com produção de $2.306 \mathrm{~kg} / \mathrm{h}$, em 2018. Houve incremento da produtividade e no número de famílias envolvidas, embora nesse período (2000-2018) haja oscilações no número de fumicultores. Disso depreende-se que a adesão à CQCT e o consequente comprometimento com a aceitação das cláusulas do documento deixaram uma lacuna quanto à substituição do fumo por outro cultivo, com patamar adequado de rentabilidade.

A ambiguidade do governo brasileiro em relação à CQCT fica evidente. Numa mão adota uma postura politicamente correta, banindo o fumo do espaço público, diminuindo o número de fumantes $^{\text {iv }}$, dentre outras medidas; noutra mão, oficialmente, o Ministério do Abastecimento, Agricultura e Pecuária MAPA apresenta o fumo como produto de exportação, para o incremento da balança comercial.

Em documento chamado Projeção do agronegócio 2017/27 e 2018/28, do MAPA, com o objetivo de apontar direções ao desenvolvimento e subsidiar aos formuladores de políticas públicas, apontando as tendências dos principais produtos do agronegócio brasileiro, o Ministério justificativa a razão e a importância do tabaco constar no documento:

No ano de 2017, fumo e seus produtos geraram ao país uma receita de exportação de US\$2,0 bilhões. Nestes últimos 12 meses, até maio de 2018, o faturamento da Balança Comercial devido ao fumo foi de US\$2,34 bilhões. A produção projetada para 2027/28 é de 967 mil toneladas. A área projetada para os próximos 10 anos é de 412 mil hectares (MAPA, 2018, p. 68).

As projeções do MAPA para 2027/2028 não levam em consideração as variações oscilatórias da produção do fumo no sul do país, que concentra $97 \%$ dos produtores, e não há indicativos de ampliação da atividade e da área plantada. A variação em 17,9\% em relação a 2017/2018, como aponta o documento, é um otimismo que não encontra respaldo nos dados obtidos 
no trabalho de campo.

\section{O campo da fumicultura}

Antes de entrar nos meandros específicos da dimensão regional e local dos fumicultores em pequena propriedade, o ponto inicial será apresentar quem é quem nesse campo do tabaco, no âmbito internacional, nacional e regional. Tomamos a noção de campo, na acepção de Pierre Bourdieu, como espaço multidimensional, no qual os agentes ocupam posições hierárquicas, encontram-se em lugares diferenciados, polarizados, disputando recursos, postos, bens, capitais, relações de poder. As posições estão demarcadas, de acordo com as aquelas já capitalizadas nas lutas anteriores. Consequentemente, é uma luta desigual. (BOURDIEU, 1989, p.64-70). Levando em conta o contexto de economia globalizada no qual se inserem os agentes, corporações da indústria do tabaco e a cadeia e seus elos, até chegar ao pequeno produtor, ações orientam-se pelo mercado financeiro, mas com vistas à capilaridade da OMS por meio dos pactos firmados.

Do ponto de vista das corporações do tabaco, situadas no sul do Brasil, mesmo que estabeleçam mercado competitivo entre si, ante ameaças da Convenção-Quadro e de ações judiciais ingressadas pelo público consumidor acometido por doenças atribuídas ao tabagismo, valem-se de medidas protetivas e estabelecem suas alianças. Passam a usar de estratégias de empresas para salvaguarda de seus capitais. ABIFUMO (Associação Brasileira da Indústria do Fumo) é a agência que atua como órgão de defesa dos interesses das instituições produtoras e similares na orientação das demandas decorrentes do público consumidor ou ex-consumidor. Orienta, igualmente, as corporações nas medidas considerada conflitivas frente ao Estado. Dentre as corporações que agem no sul do Brasil destacam-se a BAT (British American Tobacco), considerada a maior e mais influente companhia de tabaco do Brasil, por meio de sua subsidiária Souza Cruz, coligada nos Estados Unidos da América à Brown \& Willianson Tobacco Corporation, cuja sede fica em Londres e com ramificações em mais de duzentos países. Ao lado desta situa-se a Universal Leaf Tobaccos, líder mundial no processamento e comércio do fumo em folhas e principal fornecedora da Philip Morris Brasil; CTA (Continental Tobaccos Alliance), empresa associada à norte-americana G.F. Vaughan Tobacco Co. Inc.; Kannenberg Barker Hail \& Cotton Tabaco Ltda, dentre outras. Embora a maior fatia do mercado no sul do Brasil esteja nãos da Souza Cruz-BAT, as empresas mencionadas são igualmente as integradoras e controlam a cadeia produtiva do tabaco, vendendo a tecnologia, agrotóxicos, fazendo a mediação com instituição bancária, fixando o preço e avaliando e classificando o produto. O processo, a orientação, emana das empresas integradoras, cujos serviços e vínculos são firmados por contratos, gerando relação de dependência com a empresa. Atuam como “instituições totais", numa licença a Goffman (1974), coordenando a cadeia produtiva da semente ao cigarro e à exportação produto. Na defesa dos interesses das corporações há ações dos sindicatos 
patronais, como o Sindifumo (Sindicato da Indústria do Fumo), Sinditabaco (Sindicato das Indústrias da Região do Brasil).

Uma posição do campo é ocupada por instituições financeiras, a exemplo do BACEN (Banco Central). A partir de 2001 há resoluções do Bacen restringindo o acesso à produção do fumo por meio do PRONAF (Programa Nacional de Fortalecimento da Agricultura Familiar), com juros favoráveis, o que leva o setor fumageiro a migrar a outras carteiras creditícias em busca de financiamento para construção de galpões, compra de equipamentos e custeio. Esforços foram envidados pelo setor do agronegócio para inclusão dos produtores de fumo no Pronaf e junto ao BNDES (Banco Nacional de Desenvolvimento Econômico e Social), visando aumento da produção, em detrimento da diversificação de cultivos. A alegação tem como mote a necessidade de o Brasil manter sua posição de exportador.

Outro personagem importante é a ITGA (Associação Internacional de Produtores de Tabaco). Embora figure como produtor, sua posição é ambígua e algumas categorias de acusação o inserem no alinhamento às corporações. Em documento do INCA (2004) o então Ministro da Saúde José Temporão o considera braço das indústrias, contribuindo para o atraso da ratificação da Convenção-Quadro para o Controle do Tabaco. Em 2018, membros da ITGA fizeram campanha para a diminuição do número de famílias na atividade e o aumento da produtividade. No período anterior à COP/2018, fizeram périplo pelo sul do Brasil, em especial no Rio Grande do Sul, alertando acerca das exclusões de agricultores que ocorrerão no mercado do fumo. Outra de suas bandeiras foi a luta pela participação na Assembleia da Convenção-Quadro em Genebra, em 2018, ocasião em que entrou em conflito com o INCA.

Convenção-Quadro para o Controle do Tabaco (CQCT/OMS) e Conferência das Partes (COP). Em decorrência da ratificação da CQTC, a cada dois anos é realizada a Conferência das Partes, nominada COP. A primeira ocorreu em 2006 e a última em 2018. O setor produtivo demanda credenciar-se para participar, o que foi negado, em nome do princípio da integridade do evento. A responsabilidade técnica da equipe brasileira fica sob responsabilidade do INCA (Instituto Nacional do Câncer). Esse é um fórum de acompanhamento e operacionalização técnica e política da Convenção, ocasião em que reveem metas no âmbito da saúde e outras medidas a serem tomadas pelos governantes que firmaram o pacto. Insere-se aqui o aparato a quem foram delegadas atribuições em decorrência da Convenção-Quadro, tal como, o Ministério de Saúde, Anvisa, INCA e demais Ministérios e órgãos, cujas funções se confrontam com as das corporações. Se, de um lado, já foi possível diminuir o tabagismo, as estratégias do setor produtivo são redobradas para manterse na produção e na exportação.

Uma disputa é estabelecida pelo INCA, Anvisa e Vigitel à medida que apresentam os dados dos malefícios do tabaco e os números da diminuição de fumantes no país, como resultado 
das metas da CQCT. De outro lado, sem responder a essas questões, o setor fumageiro encontra forma de tergiversar e apresentar seu compromisso com a sustentabilidade, o "mundo verde" das campanhas, dos patrocínios, como forma de contribuir, consolidar a violência doce.

Se, de um lado, temos o Ministério da Saúde com pauta claramente definida, de outro, figura Ministério da Agricultura, Pecuária e Abastecimento, que hoje envolve as ações do anterior Ministério do Desenvolvimento Agrário, a quem caberia a formulação e execução de políticas para a transição ao cultivo sustentável, migração do fumo a outros cultivos, considerados viáveis e rentáveis, mas que tem apresentado propostas tímidas. Ao contrário, não desestimulou a exportação do fumo. Paradoxos e ambiguidades entre os ministérios, é o que se observa.

AFUBRA, criada em 1955, tem como interesse representar os fumicultores e atuar como entidade creditícia. A AFUBRA tem usado de estratégia de desestimular o aumento do plantio de área, face a novas políticas de consumo e das indústrias tabageiras no contexto internacional. Opera junto aos demais agentes do campo, ora em postura conciliatória, ora em enfrentando.

Um desdobramento minucioso incluiria sindicatos de trabalhadores rurais, secretarias estaduais de agricultura, secretarias municipais de agricultura. Estas são, por excelência, o ponto de apoio do agricultor. No entanto, quando este qualifica o serviço técnico da empresa integradora de melhor atendimento que o suporte público, a concorrência torna-se difícil.

\section{E por que a fumicultora persiste?}

Esta foi uma questão que nos acompanhou no trabalho de campo. A primeira resposta é a da rentabilidade da atividade, de modo que a principal atividade que gera renda é o fumo e, secundariamente, a produção leiteira. Alegam que a fumicultura é a única atividade com lucratividade capaz de proporcionar investimentos em áreas reduzidas. Arrolam a aquisição de bens a partir do cultivo do fumo. Por exemplo, uma família narra que conseguiu adquirir sua área terra, outra conseguiu construir e ampliar a casa e comprar carro (parte foi financiada), bem como custear estudos de filhos (curso superior). Neste último caso trata-se de família que planta área de 5 hectares, acima da média. A substituição do fumo por outro cultivo não se configura no horizonte desses trabalhadores. $\mathrm{O}$ argumento utilizado é de que as culturas, como milho, feijão, apresentam um alto custo de produção e a rentabilidade é baixa. Segundo alguns agricultores, encontram dificuldades de migrarem para outras atividades que exigem maiores investimentos em tecnologias e recursos. Esse discurso também é o da AFUBRA. Onde inicia um e termina outro é difícil de estabelecer.

A explicação da presidente do Sindicato dos Trabalhadores na Agricultura Familiar de Coronel Freitas e Região é de que vários agricultores tentaram mudar de atividade, mas como as 
áreas são minifúndios e a renda do produto é considerada significativa no montante final, optaram pelo retorno ou permanência na atividade. Neste caso, trata-se da premência financeira e não de escolha do ramo de atuação. No caso, o que ocorre é o oposto do previsto na Convenção-Quadro, são os agricultores que, deixando outros cultivos, buscaram o fumo. São indicativos de que não veem políticas no horizonte para sair desse plantio. O que pode ocorrer é a exclusão pela empresa integradora por não atingirem as metas.

Além disso, entre os produtores que fizeram a migração das culturas de milho e feijão para o plantio do tabaco, a alegação principal desta mudança reside na integração com as indústrias. Avaliam, em parte, favoravelmente a integração, que lhes garante a compra da produção, os preços sempre corrigidos e fixados no início de colheita. E o fundamental é que a renda bruta de um hectare de tabaco equivale a mais de seis hectares de feijão ou de milho, quando cultivados com pouca tecnologia ou no sistema tradicional.

Questionados quanto ao futuro da atividade, alguns responderam que não pretendem parar de produzir fumo tão cedo. Sabem que em algumas regiões o fumo está sendo produzido com o uso de tecnologias do plantio à colheita, em áreas maiores, com uso de máquinas e alta produtividade por hectare. Avaliam que haverá exclusão de uma boa parte dos produtores, porque há necessidade de investimento. Relatam que hoje quem produz menos de 20.000 plantas pode ser considerado excluído. Porém, alguns, cujos filhos já saíram da propriedade, devido à falta de mão de obra e com a faixa etária em declínio, afirmam que irão produzir fumo por médio e curto prazo, até poderem usufruir a aposentadoria. Outros irão continuar somente com o leite ou com bovino de corte.

No cultivo do tabaco há utilização de agroquímicos. Muitas vezes os agroquímicos utilizados no cultivo do fumo são tratados como "medicamentos", "remédios". Na sua classificação é comum incluir Rovralv, usado para pragas e insetos, como não sendo perigoso. Conhecem as habilidades para o manejo e dizem saber evitar problemas. Se a noção de perigo for relacional, perigoso seria o Premiplus, classificado pelo Ministério da Agricultura como muito perigoso do ponto de vista ambiental (toxicologicamente, pertence à classe I, extremamente tóxico). "Tem que se cuidar, pois ele derrete o broto do fumo e cola, é perigoso, tem que se cuidar".

$\mathrm{O}$ uso de inseticidas e congêneres no fumo é naturalizado. A primeira reação é o comparativo com o tomate. Afirmam que na produção de certas hortaliças usam os mesmos inseticidas. No fumo aplicam inseticida uma vez ou duas ou até nenhuma; na produção de hortaliças aplicam toda semana. Um argumento que aparece com frequência é de que no cultivo do trigo e do feijão aplicam "os remédios" uma semana antes de colher. Em outras cultivares usam maiores concentrações e dosagens, usando a lógica do efeito de "veneno" estar na dosagem.

Da integração, é ressaltado como favorável o comprometimento da integradora com a 
compra da safra, embora seja essa quem faça o preço. A produção é realizada dentro do planejado e a integradora entrega o pacote de venenos, sem necessidade de deslocamentos a agropecuárias e de desembolso para a aquisição. $\mathrm{O}$ discurso em relação às integradoras torna-se tenso quando se refere à classificação do fumo, sob a qual não têm controle, e ao preço. "É boa, só que eles fazem o preço e nós somos peões, ela manda tudo, mas faz o preço".

Na propriedade, o fumo é separado em três classes $\mathrm{X}$ (folhas de baixo), $\mathrm{C}$ (folhas do meio), B (folhas da ponta - melhor). Já a classificação da empresa "torra o agricultor" conforme a classificação define o preço. Na classificação da empresa há novos desdobramentos dos quais o produtor não participa: X1, X2, X3, XL, X1L, X2L, XK, e o resultado é o preço que baixa.

Há aqueles que destacam que o contrato assinado no momento do pedido de insumos para safra é elaborado em função da estimativa de produção, mas quanto ao preço a ser pago por esta, não consta no contrato. Caso a safra não atinja a meta de produção por três anos seguidos, a primeira medida adotada pela empresa integradora é excluir o produtor. Alguns dos entrevistados relataram que o sistema não pode ser considerado "integração", uma vez que a empresa "são os donos, mandam no agricultor". "Na hora de fazer o preço, eles fazem e somos obrigados a fazer tudo o que eles querem. Eles têm justificativa na hora de vender e comprar. O produtor tem que acatar o que eles dizem, tanto que assinam o contrato na hora do pedido para constar a estimativa de produção, mas com relação ao preço a ser pago não consta no contrato. Acho que integração tem que ser de forma a ter entendimento.

A literatura é crítica em relação à integração pela subordinação e dependência em relação à integradora. Num primeiro momento, as explicações em campo soam estranhas, quando as avaliações são favoráveis. Mais estranhas ainda quando alegam que não migram para outros cultivos, como o feijão, pela remuneração e por não haver integração, explicitada no suporte técnico e no suprimento dos insumos. Como já explicitamos, dispomos apenas de resultados preliminares, mas não deixam de causar inquietações.

No que diz respeito às políticas governamentais voltadas ao setor fumageiro, temos numa direção a Convenção-Quadro de Combate ao Tabaco com leque de ações, apresentando, operacionalmente, os efeitos desses anos de atividade. No setor produtivo, até o governo Dilma, havia dois ministérios para tratar da agricultura, o MAPA, voltado ao agronegócio, e o Ministério do Desenvolvimento Agrário, com vistas à agricultura de pequeno porte. Com a fusão dos ministérios, o primeiro responde pelos interesses gerais. Como a fumicultura é voltada, basicamente, à exportação, passou a figurar nas páginas do MAPA, como agronegócio.

O setor de financiamento, por meio das Resoluções do Bacen, vem tomando medidas de restrição de financiamento ao custeio do fumo, estabelecendo percentuais trienais para o aumento do cultivo de produtos diversificados na propriedade. Embora a medida seja correta, apostando numa 
mudança gradual, os agricultores apostam na permanência, lembrando que alguns vieram do setor de grãos para o do fumo.

O que ocorre é que as ações do cultivo do fumo são avaliadas unicamente do ponto de vista do ganho e da perda. O passivo ambiental, o agravo à saúde, o trabalho penoso e insalubre parece não estarem no cômputo. Há uma crença de permanecer na atividade pelo maior tempo possível e amealhar recursos. O agronegócio, mesmo reduzindo o número de produtores, vem contando com um público de fidelidade. As políticas públicas, aquelas sob o âmbito do INCA, estatisticamente, apresentaram resultados com a diminuição de fumantes. No entanto, há paradoxos entre as ações governamentais, que correm em paralelo.

\section{REFERÊNCIAS}

ASSOCIAÇÃO DOS FUMICULTORES DO BRASIL. AFUBRA. https://www.afubra.com.br/ acessos em 15 de fevereiro de 2019, 13 de março de 2019.

ANTONIL, André João. Cultura e opulência do Brazil, por suas drogas e minas, com várias notícias curiosas de fazer o assucar; plantar e beneficiar o tabaco; tirar ouro das minas e descobrir as de prata e dos grandes Emolumentos que esta conquista da América Meridional dá ao Reino de Portugal com estes e outros gêneros e contratos reaes. Rio de Janeiro: Casa de Souza e Com., 1837.

BOURDIEU, Pierre. O poder simbólico. Rio de Janeiro: Bertrand Brasil, 1989.

BRASIL. Decreto 5658, de 02 de janeiro de 2006. Disponível http://www.planalto.gov.br/ccivil_03/_Ato2004-2006/2006/Decreto/D5658.htm. Acesso em 13 de março de 2019.

. BANCO CENTRAL. Resolução 3.559 de 28/03/2008. Disponível

https://www.bcb.gov.br/Htms/Normativ/RESOLUCAO3559.pdf acesso em21 de maio de 2019.

Resolução 4.107, de 28 de junho de 2012. Disponível

.https://www.bcb.gov.br/htms/normativ/RESOLUCAO4107 acesso em 21 de maio de 2019.

Resolução 4.483, de 05 de maio de 2016. Disponível

https://www.bcb.gov.br/estabilidadefinanceira/exibenormativo?tipo=Resolu\%C3\%A7\%C3\%A3o \&numero $=4483$ acesso em 21 de maio de 2019

GOFFMAN, E. Manicômios, prisões e conventos. São Paulo: Perspectivas, 1974.

GRIGNON, Claude. Le paysan inclassable. Actes de la Recherche en Sciences Sociales (4), 1975, p. 82-87.

INSTITUTO NACIONAL DO CÂNCER - INCA. Observatório de Politica Nacional de Controle ao Tabaco. https://www.inca.gov.br/en/node/1419. Acesso em 21 de maio de 2019.

LAPA, José Roberto do Amaral. Esquema para um estudo do tabaco baiano no período colonial. Afro-Asiático: Salvador, 6-7, jun-dez, 1968.

MINISTERIO DE AGRICULTURA, PECUÁRIO E ABASTECIMENTO - MAPA- Projeções do agronegócio. Brasil 2017/18 a 2017/28. Projeções de longo prazo. Brasília: MAPA, 2018. Acessível. http://www.agricultura.gov.br/assuntos/politica-agricola/todas-publicacoes-de-politica- 
agricola/projecoes-do-agronegocio/banner_site-03-03-1.png/view Acesso em 10 de abril de 2019.

\author{
MINISTÉRIO DA SAÚDE. SECRETARIA DE ATENÇÃO À SAÚDE. INSTITUTO \\ NACIONAL DO CÂNCER. A ratificação da convenção-quadro para o controle do tabaco \\ pelo Brasil: mitos e verdade. Rio de Janeiro: INCA, 2004.
}

PRADO JÚNIOR, Caio. Formação do Brasil Contemporâneo: Colônia. 23. ed. São Paulo:

Brasiliense, 2004. [1942]

NARDI, Jean Batiste. O fumo no Brasil Colônia. São Paulo: Brasilense, 1987

PAULILO, M. I. S. Produtor e agroindústria: consensos e dissensos (o caso de Santa Catarina). Florianópolis: Universidade Federal de Santa Catarina, 1990.

SOUZA CRUZ.

http://www.souzacruz.com.br/group/sites/SOU_AG6LVH.nsf/vwPagesWebLive/DOAG7DXA. Acesso em 10 de abril de 2019.

SZMRECSÁNYI,T. Pequena História da Agricultura no Brasil. São Paulo: Contexto, 1990.

VIGITEL. Base de dados - meta dados - MS - vigilância de doenças por inquérito telefônico Vigitel. Disponível. https://ces.ibge.gov.br/base-de-dados/metadados/ministerio-dasaude/vigilancia-de-doencas-cronicas-por-inquerito-telefonico-vigitel. Acesso em 15 de maio de 2019.b

VOGT, O. P. A produção de fumo em Santa Cruz do Sul - RS, 1849-1993. Santa Cruz do Sul: Edunisc, 1997.

Submetido em: $15 / 01 / 2020$

Aprovado em: 20/02/2020

Publicado: $1 \% 5 / 2020$

\footnotetext{
* Programas de Ciências Ambientais em Direito e em Ciências Ambientais da Unochapecó.

** Professora dos programas de pós-graduação em Direito e em Ciências Ambientais da Unochapecó.

i Disponível http://www.agronovas.com.br/exportacao-de-tabaco-2/; /www.agrolink.com.br/noticias/exportacoes-de-tabaco-aumentam-com-embarques-atrasados_419304.html. Consultado em 10 de abril de 2019; /www.inca.gov.br/observatorio-da-politica-nacional-de-controle-dotabaco/exportacao-fumo-e-seus-derivados.

2 "O objetivo da presente Convenção e de seus protocolos é proteger as gerações presentes e futuras das devastadoras conseqüências sanitárias, sociais, ambientais e econômicas geradas pelo consumo e pela exposição à fumaça do tabaco, proporcionando uma referência para as medidas de controle do tabaco, a serem implementadas pelas Partes nos níveis nacional, regional e internacional, a fim de reduzir de maneira contínua e substancial a prevalência do consumo e a exposição à fumaça do tabaco. (artigo 3. Decreto 5658/2006).
}

\footnotetext{
iii Visitar os sítios das empresas integradoras revela-se num roteiro da banalização de categorias alusivas à ambientalização, sustentabilidade e congêneres.

iv Pesquisa da Vigitel aponta que, em 2006, 15,70\% dos brasileiros declaravam-se fumantes. No ano de 2018 esse número era de 9,3\%. A pesquisa Vigitel é realizada pela Secretaria da Vigilância em Saúde (SVS), do Ministério da Saúde.
} 
${ }^{\vee}$ Rovral classificação toxicológica é Classe II, ou seja, altamente tóxico e produto perigoso ao meio ambiente. 